\title{
On the Syntax of Topic and Focus in Chinese*
}

\author{
Linda Badan and Francesca Del Gobbo \\ University of Padova and Ca' Foscari University of Venice/University of Southern California \\ linda.badan@unipd.it; fdelgobb@unive.it
}

\section{Framework and Aims}

The aim of this paper is to provide a preliminary study of the Left Periphery (LP) of Mandarin Chinese, following the basic lines of the "Cartographic Project" (Cinque, 1999, 2002; Rizzi, 2004; Belletti, 2004) and of the fine structure of CP sketched by Rizzi (1997), and further developed in Benincà (2001), Benincà \& Poletto (2004) and Benincà (2004).

Benincà \& Poletto (2004) and Benincà (2004) differentiate between Topics and Foci. Topics are non-operator elements, linked to a clitic or a pro and not showing WCO effects. Foci are operator-like elements: they leave a trace, and show WCO effects. Both Topic and Focus are further distinguished: the authors provide evidence to distinguish Hanging Topics (HT) vs. Left Dislocated ones (LD). They also discuss the position of Scene Setting adverbs and isolate the lowest position inside the Topic field, where List Interpretation Topics (LI) occur. As for Focus, they mainly divide it into Contrastive Focus and Informational Focus. Their final proposed structure is:

\section{(1) $[[\mathrm{HT}][[$ Scene Setting $][[\mathrm{LD}][[\mathrm{LI}][[$ Contr Focus] [[Inf Focus]]]]]]]}

Our goal is first of all to find out whether Chinese shows the same ordering restrictions found in Italian with respect to Topic and Focus. As for Topic, we shall concentrate our attention onto HT and LD. We shall also investigate whether Chinese allows focalization strategies in the Left Periphery, or it only allows in-situ and/or preverbal Focus (SOV instances, see Shyu (1995)). Chinese has been claimed to be a Topic-Prominent language ( $\mathrm{Li}$ and Thompson, 1976). We aim at discovering how this claim translates in a theory of the fine structure of the Left Periphery. More specifically, Chinese has been claimed to have two types of Topics: base-generated ones ${ }^{1}$ and moved ones. We investigate how such a claim can be represented in a structure as the one proposed in (1).

\footnotetext{
* This paper is the result of collaboration between the two authors. For the purpose of Italian academia, Badan takes responsibility for the sections from page 1 to page 11 and Del Gobbo for those from page 12 to page 24. For their insightful comments, we would like to thank Paola Benincà, Lisa Cheng, Guglielmo Cinque, Jim Huang, Marie-Claude Paris, and Waltraud Paul. Section 3 was presented at University of Padova and at the Journées d'Etudes: La Peripherie Gauche de la phrase, Structure et Functions, (Federation Typologie et Universaux Linguistiques-CNRS, Paris). Different versions of the paper were presented at the Paris Meeting on East Asian Linguistics, CRLAO, France, at WECOL 2006, Fresno, CA, at the 1st Chicago Workshop in Chinese Linguistics and at the LSA 2007 Meeting in Anaheim, CA. We thank the audiences there, and in particular Adriana Belletti, Jason Merchant, Cecilia Poletto, JeanYves Pollock, Luigi Rizzi, Patricia Schneider-Zioga, Anne Sturgeon and Maria Luisa Zubizarreta for their useful suggestions. For their judgements of Mandarin Chinese data, we are also extremely thankful to the following native speakers: Qing Qing, Miao Zheng and Li Jun. The research conducted for this paper was partially funded by the Italian Ministry of Education, University and Research, through the 'Rientro dei Cervelli' fellowship for Francesca Del Gobbo. All errors remain our responsibility.

1 'Aboutness topics' are uncontroversially assumed to be base-generated, as there is no gap in the sentence to which the topic can be linked to. We provide an example below:

(i) Shuiguo, wo zui xihuan xiangjiao.

fruit I most like banana

"As for fruit, I like bananas most."

Throughout the article, whenever we use the term 'aboutness topic', we mean examples of this kind.
} 


\section{Previous studies on Topic and Focus in Mandarin Chinese}

A lot of research has been carried out regarding topicalization and focalization in Chinese. In this section, we concentrate on some of the findings that are more relevant for our investigation.

\subsection{On Topicalization}

Shyu (1995) distinguishes between two sentence-initial elements: lian-Focus (even-Focus) and Topic.

(2) Lian zhe ben shu Zhangsan dou/ye mai le. ${ }^{2,3}$ even this-CL book Zhangsan all/also buy PERF "Even this book, Zhangsan also bought."

(3) Zhe ben shu Zhangsan mai le. ${ }^{4}$ this-CL book Zhangsan buy PERF "This book Zhangsan bought."

(2) illustrates the lian-Focus construction. Lian (even) is on the left of the focalized element, its presence is optional. The two adverbs dou ("all") and ye ("also") - in complementary distribution with each other - are obligatory, even in the absence of lian, and are located to the left of the verb. (3) shows a DP topicalized to the first position of the sentence.

Shyu claims that both elements can be either moved (to Spec of TopicP) or base-generated (at the IP adjunct site), and compete for the same landing or base-generation site. She furthermore claims that:

1. (Pseudo-)resumptive pronouns ${ }^{5}$ are allowed only if an 'aboutness' relation can be established, and only in the cases of base-generation (whether of lian-Focus or of Topic (her 'major subject'));

2. WCO effects are observed only with what she defines 'long-distance liantopicalizations'.

There has always been a debate in the literature regarding the derivation of topic structures in Chinese. More specifically, some authors (Huang, 1982, 1987; Li, 1990; Qu, 1994; Shi, 1992a; Shyu, 1995) claim that Topics are derived by movement, while some others (Xu and Langendoen, 1985 and $\mathrm{Xu}, 1986$ ) claim that they are base-generated. Here, we will follow Li (2000) in taking the following facts as evidence for the need of a movement process to derive topic structures:

\footnotetext{
${ }^{2}$ The following abbreviations are used in glossing examples: BA particle for introducing preposed object; CL classifier; DE determination particle; EXP experiential aspect; MOD modal particle; PART particle; PERF perfective aspect; REL particle for relative clause modification.

3 "The role of lian consists in picking out of a class of elements that are scanned by ye and dou one (or more) element(s) which has/ve the least probability of possessing the property predicated of the whole class and in asserting that this/these elements also possess(es) this property. To the class of elements which serves as a reference class, one more element- which was not expected to possess the same property as predicated of the reference class- is added." (Paris, 1979a, pg.66). According to Shyu (1995), the interpretation of lian..doulye mirrors exactly the meaning of English even: 'everything... including.' Lian in fact literally means 'including, connecting,' and it exhaustively quantifies all members in an understood domain. The VP quantifier dou/ye 'all/ also' relates relevant events under discussion with lian-elements. Hence, based on their similar semantic interpretation (that of exhaustively screening elements in given discourse domains) Shyu (1995) claims that lian-NPs behave like universal QPs. The only difference is that lian..dou/ye presupposes the existence of a pragmatic likelihood scale associated with the sentence (see Horn (1969), Fauconnier (1975), Karttunen \& Peters (1979) among others), but regular universal QPs do not.

${ }^{4}$ We would like to note here that all Topics in Chinese can be separated from the rest of the sentence by means of a special intonational contour or by a clearly audible pause, which can be reinforced by a particle acting as a Topicmarker a (ya), ne, me, ba (Paul, 2005; Shi, 2000; Gasde, 1999; Gasde \& Paul, 1996; Li Boya, 2006).

${ }^{5}$ Shyu (1995) introduces the term 'pseudo-resumptive pronoun' to indicate the overt realization of a pro, differentiating it from what a resumptive pronoun is traditionally assumed to be, namely the overt realization of a variable.
} 
(4) i. A PP, which cannot be a pro, can be topicalized; ${ }^{6}$

ii. Part of an idiomatic expression can be topicalized;

iii. The displaced PP or idiom chunk can be separated from its original position cross clauses (long distance dependency relation) but cannot be separated by an island boundary (island conditions)

iv. Reconstruction is possible as illustrated by the binding of anaphors.

$\mathrm{Li}$ (2000) further argues that reconstruction is available only if needed, a claim that is consistent with Sauerland's (1998) account of reconstruction in relative clauses. Namely, you reconstruct in LF only if you need to.

So, we can conclude with Huang (1982) and $\mathrm{Li}(2000)$ that topic structures with a gap can be derived by movement; and that there is a need to distinguish cases where movement occurs (the gap in these cases is a trace) from cases where no movement occurs (either the gap is a pro or there is no gap). This also takes care of the well-know subject-object asymmetry for island effects. ${ }^{7}$ Even though Li (2000) doesn't say what regulates the occurrence of resumptive pronouns, she acknowledges the fact that topic structures can have a resumptive pronoun. In these cases, she shows that reconstruction doesn't occur. We shall take this to mean that topic structures with resumptive pronouns are base-generated, in agreement with Shyu (1995) and we shall assume that in Chinese Hanging Topics are base-generated, while Left Dislocated Topics are moved. ${ }^{8}$

As for base-generated topic structures without a real resumptive element or a pro or a trace in the sentence, hence for "Aboutness Relationship" topic structures, we shall assume that these are base-generated as well. We shall show though that they differ from Hanging Topics.

We said that gapped topic structures are generated by movement. Following Li (2000), and Huang, Li and Li (forthcoming), we shall assume that such movement is of the A'-type.

\subsection{On Focalization}

Gao (1994) and Paris $(1998,1999)$ consider two kinds of Foci (NEW information) in Chinese:

1. Lian-Focus (even-Focus), always in preverbal position (see ex. (2));

${ }^{6}$ The ungrammaticality of the following example, from Paul (personal communication) may be due to independent reasons:

(i) *Cong Beijing, ta mingtian hui Shanghai.

from Beijing he tomorrow come-back Shanghai

??'FROM BEIJING, tomorrow he goes back to Shanghai.’

Notice in fact that the translation of (i) in English is marginal at best. Notice moreover that the possibility of moving a PP doesn't seem to be related to its status as a complement or an adjunct, as the following examples from Li (2000) show:

(ii) a. Dui Zhangsan, wo zhidao ta $\mathrm{t}$ bu zenme guanxin.

to Zhangsan I know he not how care

'To Zhangsan, I know he does not quite care for.'

b. Cong zhejia yinhang, wo zhidao women keyi t jiedao henduo qian.

from this bank I know we can borrow much money

'From this bank, I know we can borrow a lot of money.'

c. Gen zhe zhong laoshi, wo zhidao wo t yiding xue-bu-hao

with this kind teacher I know I certainly study-not-well

'With this kind of teacher, I know I certainly will not learn well.'

\footnotetext{
${ }^{7}$ Huang (1982) noticed that the Complex NP Constraint and the Left Branch Condition seem to have an island effect on extraction only when a given island occurs in object position, not when it occurs in subject position. This is accounted for by the possibility in Chinese of having a pro in the gap position, when the clause that contains the gap is itself in subject position, see Huang's (1982) Generalized Control Rule.

${ }^{8}$ Notice that traditionally (see Smits 1989 and Cinque 1990), the term Left Dislocation was used for cases that do not involve movement, as in John, I like him.
} 
(5) Zhangsan lian zhe ben shu dou/ye mai le.

Zhangsan even this CL book all/also buy PERF

Lit.: "Zhangsan even this book also bought."

(6) *Zhangsan dou/ye mai le lian zhe ben shu. Zhangsan all/also buy PERF even this CL book

Lit.: "Zhangsan also bought even this book."

2. Focus with contrastive stress (indicated in this article by the use of capital letters), without any Focus Marker, in-situ:

(7) a. ZHANGSAN chi le yi ge pinguo.

(Gao, 1994: 1 a.-d.)

Zhangsan eat PERF one CL apple

"It is Zhangsan who has eaten an apple (not Lisi)."

b. Zhangsan chi le yi ge PINGGUO.

Zhangsan eat PERF one CL apple

"Zhangsan has eaten an apple (not a banana)."

c. Zhangsan chi le YI GE pingguo.

Zhangsan eat PERF one CL apple

"Zhangsan has eaten one apple (not two)"

d. Zhangsan CHI LE yi ge pinguo.

Zhangsan eat PERF one CL apple

"Zhangsan has eaten an apple (not cut one)"

(7a-d) show that the focused expression bears sentential stress and remains in its base-generated position. Gao (1994) claims that virtually any element in a sentence can be stressed and thus contrasted. Moreover, he adds that in-situ Focus gives new information and it can be used in question-answer pairs (Informational Focus). Thus, he reasons, it is quite understandable that in-situ Focus can be directly related to $w h$-questions. Given that Chinese is a $w h$-in-situ language and that the wh-elements are moved at LF (Huang, 1982), for the in-situ Focus structure, he likewise proposes an analysis based on LF movement.

Paul (2005) proposes the following structure for the Left Periphery in Mandarin Chinese:

(8) $C P($ force $)>$ TopicP $>$ even Focus $>I P>$..

(8) shows that in Chinese, in the CP area the TopicP is always in a position higher than the evenFocus position, in other words no topics are allowed below Focus. Paul (2006) maintains the same structure of the Left Periphery shown in (8) and furthermore analyses the Topic position from a semantic point of view. She claims that the topic position is not associated with a fixed informational value, but is open for XPs carrying new or old information alike.

The aim of our research is to provide a study of the Left Periphery in Mandarin Chinese mainly from a syntactic point of view, hence in this paper we mainly concentrate our attention on the syntactic behaviours and properties of the different projections in the LP and we discuss their semantic interpretation only marginally.

\subsection{On Movement, Resumption and WCO}

We said above that as far as Topics are concerned, we assume two possible derivations in Chinese: base-generation and movement (A'-type). As for Focus, following Gao (1994), we'll 
assume LF movement. Lian-Focus, instead, just like Topic, can be obtained either by movement or by base-generation (see Shyu, 1995).

As far as resumption is concerned, Huang, $\mathrm{Li}$ and $\mathrm{Li}$ (forthcoming) show that the order OSV (a topic structure), not the order SOV (a focus structure), allows for a coindexed pronoun in the postverbal object position:

(9) a. *Wo Zhang xiaojie ${ }_{\mathrm{i}}$ bu xiang zhui ta $\mathrm{i}_{\mathrm{i}}$ Li xiaojie $\mathrm{j}_{\mathrm{j}}$ cai hui zhui ta I Zhang Miss not want court her Li Miss only will court her

cf. b. Zhang xiaojie ${ }_{i}$, wo bu xiang zhui ta $_{\mathrm{i}}$ Zhang Miss I not want court her

"Miss Zhang, I don't want to court her."

Paris (1999), going in the same direction as Huang, Li and Li (forthcoming), maintains that the resumptive pronoun with lian-construction is only allowed with sentence-initial lian:

(10) Lian Zhangsan (a), ta $_{\mathrm{i}}$ zuotian dou mei lai. even Zhangsan PART he yesterday all not come "Even Zhangsan didn't come yesterday."

(11) Lian Zhangsan Z $_{\mathrm{i}}$ ye xiuhao le $\operatorname{ta}_{\mathrm{i} j \mathrm{j}}$ de che. even Zhangsan also repair PERF he DE car "Even Zhangsan repaired his $\mathrm{s}_{\mathrm{i} / \mathrm{j}}$ car."

(12) Lian Zhangsan (a), wo ye ti ta $_{\mathrm{i}}$ zuo fan. even Zhangsan PART I also for him make food "Zhangsan, I even cooked for him."

(13) *Wo lian Zhangsani ye ti ta $\mathrm{i}_{\mathrm{i}}$ zuo fan. I even Zhangsan also for him make food

For Shyu (1995), in lian-Focus constructions (IP-internal ones) a resumptive pronoun is not able to salvage an island violation. A lian-focalized NP in [Spec FP] does not allow overt pronominal copying, either in simplex or complex clauses. But a pseudo-resumptive pronoun can occur in the gap position inside a relative clause, to be interpreted with the base-generated S-initial lian-NP (base-generated according to Shyu) (note that dou appears in the main clause):

(14) Lian Mali $i_{i}$ Zhangsan dou taoyan [NP[CP e $_{j}$ kua-jiang $\boldsymbol{t a}_{\mathbf{i}}$ de] ren $\left.{ }_{\mathrm{j}}\right]$ even Mary Zhangsan all dislike praise she REL person

"Even for Mali $\mathrm{i}_{\mathrm{i}}$ Zhangsan dislikes the person who praises her."

The pattern then seems to be that resumption is only allowed with topicalization and with sentenceinitial lian-construction, but not with focalization (SOV and sentence-internal lian-construction are both considered focus structures, see for example Shyu (1995)). What still needs to be established is in what cases of topicalization the resumptive pronoun is allowed and in what cases it is obligatory (we'll get to this in section 3.1). As for sentence-initial lian-construction, its behaviour with respect to resumption, as well as other hints, seems to show that this construction has some characteristics of Topic and some characteristics of Focus. Here, we shall simply assume that it is sentence-initial Focus and we shall leave the task of better understanding its nature for future research.

Let's now turn to WCO. WCO effects are not observed in Chinese topicalization. See Shyu (1995) and Gasde (1999): 
(15) [Zhe tiao keai de gou $]_{\mathrm{i}}$, ta $\mathrm{ta}_{\mathrm{i}}$ de zhuren hui xihuan $t_{\mathrm{i}}$.

(Gasde, 1999) This CL lovely DE dog it DE master can like

"This lovely dog $_{\mathrm{i}}$, surely its $\mathrm{i}_{\mathrm{i}}$ master must like (it $\left.\mathrm{i}_{\mathrm{i}}\right) . "$

(16) Zhangsan Z $_{\mathrm{i}}$, piping ta $\mathrm{a}_{\mathrm{i}}$ de ren bu xihuan $t_{\mathrm{i}}$. Zhangsan criticize him REL person not like

(Shyu, 1995)

"Lit: Zhangsan ${ }_{i}$, people that criticize himi don't like $\left(\right.$ him $\left._{\mathrm{i}}\right)$."

The situation gets more complicated when we look at sentence-initial lian-constructions. According to Shyu (1995), certain cases do display WCO effects. They are long-distance moved lian-NPs, in which dou occurs in embedded clauses, as illustrated in (17).

(17) a. *Lian-NP $\mathrm{N}_{\mathrm{i}} \mathrm{Sub} \ldots \mathrm{V}$... [CP [NP..ta $\left.\left.a_{\mathrm{i} . .}\right] \boldsymbol{d o u} \mathrm{V} t_{\mathrm{i}}\right]$

b. *Lian Zhangsan ${ }_{\mathrm{i}}$ Mali renwei [CP[piping ta $\mathrm{i}_{\mathrm{i}}$ de zhe ben shu] dou hui le $t_{\mathrm{i}}$ ] even Zhangsan Mali think criticize him REL this CL book all destroy PERF

"Lit. Even Zhangsan ${ }_{i}$, Mary thinks that the book that criticizes him $_{\mathrm{i}}$ destroyed."

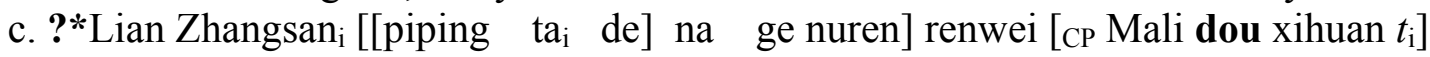
even Zhangsan criticize him REL that CL woman think Mali all like "Lit. Even Zhangsan ${ }_{i}$, the woman who criticizes him ${ }_{i}$ thinks that Mary likes."

But, interestingly, these WCO effects disappear (according to Shyu), in simple clauses:

(18) Lian-NP ${ }_{\mathrm{i}}\left[\mathrm{NP} . . \mathrm{ta}_{\mathrm{i} . .} .\right.$. ..dou $-\mathrm{V}-e c_{\mathrm{i}}$

(19) Lian Zhangsan ${ }_{\mathrm{i}}\left[\mathrm{NP}_{0}\left[e_{\mathrm{j}}\right.\right.$ piping ta $\left.\mathbf{t a}_{\mathrm{i}} \mathrm{de}\right]$ na ge nüren $\left.\mathrm{j}_{\mathrm{j}}\right]$ dou xihuan $\left.e c_{\mathrm{i}}\right]$ even Zhangsan criticize he REL that-CL woman all like

"Lit. Even Zhangsan ${ }_{i}$, that woman who criticizes him ${ }_{\mathrm{i}}$ likes."

Also, according to Shyu (1995) there are no WCO effects if the initial lian-focus construction has dou in the matrix clause:

(20) a. Lian-NP $\mathrm{i}$ S .. dou-V ... [CP $\left.\left[\mathrm{NP} \ldots t a_{\mathrm{i}} . ..\right] \mathrm{V} e c_{\mathrm{i}}\right]$

b. Lian-NP ${ }_{\mathrm{i}}\left[\mathrm{NP}\right.$...ta $\left.a_{\mathrm{i}} . ..\right]-$ dou-V.. $\left[\mathrm{CP} \mathrm{S}-\mathrm{V}-e c_{\mathrm{i}}\right]$

(21) Lian Zhangsan ${ }_{\mathrm{i}}$ Mali dou renwei [CP [NP piping $\boldsymbol{t a}_{\mathrm{i}}$ de zhe ge nüren] bu xihuan $\left(t a_{\mathrm{i}}\right)$ ] even Zhangsan Mali all think criticize him REL this CL woman not like him "Even Zhangsan ${ }_{i}$, Mary thinks that the woman that criticizes him ${ }_{i}$ dislikes."

(22) Lian Zhangsan ${ }_{\mathrm{i}}$ [NP piping $\boldsymbol{t a}_{\mathrm{i}}$ de na ge nüren] dou renwei [CP Mali xihuan $\left(t a_{\mathrm{i}}\right)$ ] even Zhangsan criticize him REL that CL woman all think Mali like him "Even Zhangsan, , the woman who criticizes him $_{\mathrm{i}}$ also thinks that Mary likes."

In summary, Shyu (1995) notices that when the lian-phrases are long-distance fronted to the matrix topic position and dou occurs in the embedded clauses, we see reconstruction effects. On the other hand, when dou occurs in matrix clauses, no obligatory reconstruction effects are observed. Shyu's (1995) explanation of the WCO effect is then that when the lian-phrase is in a sentence different from the one that contains dou, it has moved, thereby showing WCO effects, otherwise it is basegenerated. 
Differently from what has been claimed by Shyu (1995), the two sentences below show that WCO effects are observed in sentence-internal focus structures, both in cases of lian-focus, and in cases of SOV focus:

$(23) *$ Wo lian meimei $\mathrm{i}_{\mathrm{i}}$ dou [ba ta $\mathrm{a}_{\mathrm{i}}$ xihuan de wanju $]_{\mathrm{j}}$ qiang-zou le $\mathrm{t}_{\mathrm{j}}$.

$I$ even sister all BA her like DE toy rob-away PERF

Int.: 'I even stole the toy my sister likes.'

(24) *Wo Zhang xiaojie $\mathrm{i}_{\mathrm{i}}$ bu yao ta $\mathrm{t}_{\mathrm{i}}$ de nanpengyou qu $\mathrm{t}_{\mathrm{i}}$. Li xiaojie $\mathrm{j}_{\mathrm{j}}$ cai yao $\mathrm{ta}_{\mathrm{j}}$ de nanpengyou qu $\mathrm{t}_{\mathrm{j}}$.

I Zhang miss non want her DE boyfriend marry Li miss only want her DE boyfriend marry

Int.: 'Miss Zhang, I don't want her boyfriend to marry her, I only want Miss Li, her boyfriend to marry her.'

This will allow us to use WCO as a test to distinguish Focus from Topic (see section 5.4).

To summarize, sentence-internal focus structures, both the lian-focus and the SOV focus, exhibit WCO and do not permit a resumptive pronoun strategy. These characteristics confirm the hypothesis that such structures are derived via A-bar movement.

On the other hand, sentence-initial Topics do allow resumptive pronouns, and do not exhibit WCO effects. They can be derived by movement (A'-movement) or be base-generated. Sentenceinitial lian ... dou/ye constructions show WCO if lian and dou/ye are separated long-distance, but not otherwise, and do allow resumptive pronouns. Like Topics, they can be derived by movement or be base-generated.

In the following sections, we shall look at the distinction between HT and LD, and provide evidence for the existence of such distinction for Chinese as well. We shall also address the issue of Aboutness Topic vs. other kinds of Topic in Chinese. More precisely, we shall show that there is reason to distinguish Aboutness Topic from other kinds of Topics in this language.

We shall then look at the relative order between Topic and Focus elements, and we shall see that only lian-Focus is allowed in the Left Periphery in Chinese. The contrastive NP that appears in the Left Periphery will prove to be a Contrastive Topic.

\section{Hanging Topic and Left Dislocation}

In this section, we investigate Topics in Chinese. We restrict our attention to Topics that are linked to a trace, or a pro or a resumptive pronoun in the sentence, namely here we don't talk about Abountness Topics. These will be analyzed in section 4.

Our aim is to find out if there is empirical evidence to show that in Chinese as well Topics are divided into two different types, namely Hanging Topic and Left Dislocation Topic, as shown by Benincà and Poletto (2004) for Italian.

The diagnostic features to distinguish Hanging Topic from Left Dislocation Topic are listed below:

\section{- HT (Hanging Topic)}

1. HT can only be a Bare DP (it cannot be a Prepositional Phrase).

2. It does not need to agree in Case with the coreferent resumptive element inside the predicate (IP).

3. HTs always require a resumptive pronoun expressing the type of argument: it only agrees with the HT in number and gender, not in Case. 
4. It can be resumed by a tonic pronoun or an epithet.

5. Multiple Hanging Topics are not possible.

6. It can cooccur with Left Dislocation; in this case, HT always precedes LD.

- LD (Left Dislocation)

1. LD can be a Prepositional Phrase (PP).

2. It agrees in Case with the coreferent resumptive pronoun inside the predicate (IP).

3. LD elements require a resumptive pronoun (clitic, in Italian) only when they correspond to direct or partitive objects; the clitic is optional in the other cases (impossible if the type of argument has no appropriate clitic). If present, the clitic agrees with the Topic in gender, number and Case.

4. It cannot be resumed by an epithet or a tonic pronoun, only a clitic is possible.

5. Multiple Left Dislocations are possible.

6. It can cooccur with Hanging Topic; in this case, LD always follows it.

The diagnostic test based on the presence $v s$. absence of resumptive clitic pronouns is not available in Chinese, as this language does not have clitic pronouns. If the distinction between HT and LD is nevertheless present, we expect the following:

1. HT cannot be PP, while LD can;

2. HT doesn't need to agree in Case with the resumptive element;

3. Since there are no clitics in Chinese, LDs leave a gap, while HTs are resumed by an epithet or a tonic pronoun;

4. Only multiple LDs are possible;

5. The relative order is $\mathrm{HT}>\mathrm{LD}$.

\subsection{Results of the Diagnostic Tests}

Given the preceding discussion, if we have a PP in Topic position, we suppose that it would be a LD and if we have a bare DP, it would be a HT. We can then test if they need to agree in Case with a resumptive element within IP. The two examples below show that HTs, as bare DPs, do need to be linked to a resumptive pronoun but that they do not agree in Case with it.

(25) a. Zhangsan ${ }_{i}$, wo gei ta $\mathrm{i}_{\mathrm{i}}$ qu mai dongxi.

Zhangsan I to him go buy thing

"Zhangsan, I go buy things for him."

b. ??/* Zhangsan, wo qu mai dongxi

Zhangsan, I go buy thing

With LD, it is not possible to resume the Topic with a resumptive pronoun, and so we can't test whether there would be agreement in Case between the Topic and the resumptive element:

(26) ?*Gei Zhangsan, wo gei ta ji le yi feng xin. to Zhangsan I to him send PERF one CL letter

(27) Gei Zhangsan, wo ji le yi feng xin. To Zhangsan I send PERF one CL letter "To Zhangsan, I sent a letter."

The following examples show that HTs can be resumed by an ephitet in IP: 
(28) Zhangsan ${ }_{i}$, wo gei [ na ge shazi $]_{\mathrm{i}}$ ji le yi feng xin! Zhangsan $I$ to that CL imbecile send PERF one CL letter "Zhangsan, I sent a letter to that imbecile!"

In the example below, we see that with LD, a PP cannot be resumed by an ephitet in IP.

(29)?*Gei Zhangsan ${ }_{i}$, wo gei na ge shazi $\mathrm{i}_{\mathrm{i}}$ ji le yi feng xin! To Zhangsan $I$ to that CL imbecile send PERF one CL letter

When more than one element is topicalized, the result is that multiple HTs are not possible, while multiple LDs are:

(30) *Zhejia yinhang ${ }_{\mathrm{i}}$ Zhangsan $_{\mathrm{j}}$ wo zhidao women keyi cong nali $\mathrm{i}_{\mathrm{i}} \mathrm{ti} /$ wei $_{\mathrm{j}} \mathrm{ta}_{\mathrm{j}}$ jiedao hen duo qian. this-CL bank Zhangsan I know we can from there for him borrow very much money

(31) Cong zhejia yinhang ti $_{\mathrm{i}}$ wei Zhangsan , $_{\mathrm{j}}$ wo zhidao women keyi jiedao hen duo qian. LD+LD from thic-CL bank for Zhangsan I know we can borrow very much money

'From this bank, for Zhangsan, I know we can borrow a lot of money.'

When HTs and LDs occur together, we find that HT has to precede LD:

(32) ?/OK Zhangsan ${ }_{i}$, cong zhejia yinhang, wo zhidao women keyi ti/wei ta $\mathrm{i}_{\mathrm{j}}$ jiedao hen duo qian. Zhangsan from this-CL bank I know we can for him borrow very much money Lit.: 'Zhangsan, from that bank, I know we can borrow a lot of money for him.'

HT $>$ LD

(33) *Cong zhejia yinhang, Zhangsan, wo zhidao women keyi ti/wei/dui ta jiedao hen duo qian. from that-CL bank Zhangsan I know we can for him borrow very much money

\section{$\mathrm{LD}>\mathrm{HT}$}

When the element topicalized is either a subject or an object, there seems to be no way in Chinese to distinguish between a HT or a LD, as they are both necessarily realized as DPs:

(34) a. Zhangsan, wo kanjian ta le. $_{\text {l }}$.

Zhangsan I saw him MOD

"Zhangsan, I saw."

b. Zhangsan, wo kanjian $t_{\mathrm{i}}$ le.

Zhangsan, I saw MOD

"Zhangsan, I saw."

But notice that there is a difference between (34a) and (34b), namely in (34a) the Topic is linked to a resumptive pronoun, while in (34b) the Topic is linked to a trace. We know, from the results of the above tests, that multiple HTs are disallowed, while multiple LDs are possible. Also, given the fact that with PPs, HTs leave a resumptive pronoun, and LDs a gap, it is reasonable to hypothesize that this situation would generalize to cases of object and subject topicalization as well. There is obviously a way to test this: if it is true that HTs are always matched by resumptive pronouns, we 
would expect ungrammaticality in a sentence with multiple Topics with resumptive pronouns. And if it is true that LDs always leave a gap, we would expect grammaticality with multiple Topics with gaps. And this is exactly what we find, as illustrated below:

(35) * Zhangsan, , [Lisi he Xiaoyu $]_{\mathrm{j}}$, ta $\mathrm{i}_{\mathrm{i}}$ zai yuelanshi kanjian tamen $_{\mathrm{j}}$. Zhangsan Lisi and Xiaoyu he in reading room saw them

(36) Zhangsan ${ }_{\mathrm{i}}$, [Lisi he Xiaoyu $]_{\mathrm{j}}, \boldsymbol{t}_{\mathrm{i} / \mathrm{j}}$ zai yuelanshi $\quad$ kanjian $\boldsymbol{t}_{\mathrm{j} / \mathrm{i}}$.

Zhangsan Lisi and Xiaoyu in reading room saw

"Zhangsan, Lisi and Xiaoyu, he saw them in the reading room."

"Zhangsan, Lisi and Xiaoyu, they saw him in the reading room."

We then assume from now on that the difference between (34a) and (34b) is not due to the optionality of the resumptive pronoun, but instead to the fact that in (34a) the Topic is HT and as such it is linked to a resumptive pronoun and in (34b) the Topic is LD, and therefore it is linked to a trace.

Summarizing, on the basis of the empirical diagnostic tests illustrated above, we identify two different types of thematized arguments in Chinese: the traditional Topic position is split into two positions: Hanging Topic (HT) and Left Dislocation (LD).

\subsection{Embedded Topics}

As already noticed by Huang (1982), topics can be embedded. The following examples show that, at least in isolation, both HT and LD are allowed in embedded contexts:

(37) Wo renwei gen na ge nuhaizi Zhangsan conglai mei shuo-hua.

I think with that CL girl Zhangsan never not talk-word

"I think that to that girl Zhangsan has never talked."

(38) Wo renwei na ge nuhaizi $\mathrm{i}_{\mathrm{i}}$ Zhangsan conglai mei you gen $\mathrm{ta}_{\mathrm{i}}$ shuo-hua.

I think that CL girl Zhangsan never not have with her talk-word

"I think that that girl, Zhangsan has never talked to her."

It also seems that when a complementizer (COMP) is present, HT precedes the complementizer, while LD follows it: ${ }^{9}$

(39)*Zicong na ge nuhaizi ni gen ta jie hun le, zhe-ge jia jiu meiyou yike anning. since thatCLgirl you with her marry MOD this CLhouse then not have a moment quietness

(40) Na ge nuhaizi zicong ni gen ta jie hun le, zhe ge jia jiu meiyou yike anning. thatCL girl since you with her marry MOD this CLhouse then not have a moment quietness

\footnotetext{
${ }^{9}$ In order to test the occurrence of Topics of either type (HT and LD) with complementizers, we had to resort to subordinate sentences. For these, at least two analysis are available. According to one analysis (see Gasde \& Paul (1996) and $\mathrm{Lu}$ (2003), the subordinate clause is in the position of TopicP preceding the matrix. A nominal preceding such subordinate clause is analyzed as sitting in a higher TopicP. An alternative analysis, following Chierchia's (1995) account of if/when-clauses, is to consider the subordinate clause as a CP adjoined to the matrix IP. Within such an analysis, the nominal preceding the subordinate clause would be in the Spec position of a Hanging TopicP that takes the subordinate $\mathrm{CP}$ as its complement. Notice that the main reason to propose that the first nominal would be in its own TopicP is related to its impossibility to move from an adjunct. But within a theory of the Left Periphery as the one in Benincà and Poletto (2004), we can just assume that the first nominal in the sentence is in a HT position of the embedded clause, capturing this way the fact that it has scope only on the subordinate clause, and not also on the matrix one.
} 
"That girl, ever since you married, this house hasn't had a quiet moment."

(41) *Yinwei Zhangsan ni bu yao gen ta shuohua, wo zhihao qing le Lisi bangmang. because Zhangsan you not want with him talk, I be obliged ask PERF Lisi help

(42) Zhangsan (a), yinwei ni bu yao gen ta shuohua, wo zhihao qing le Lisi bangmang. Zhangsan PART because you not want with him talk, I be obliged ask PERF Lisi help “Zhangsan, because you didn't want to talk to him, I had to ask Lisi to help.

The examples in (39)-(42) show that HT has to precede the complementizer. The examples that follow are aimed at testing the order between LD and COMP:

(43) Yinwei gen Zhangsan ni bu yao shuohua, wo zhihao qing le Lisi bangmang. because with Zhangsan you not want talk, I be obliged ask PERF Lisi help "Because to Zhangsan, you didn't want to talk, I had to ask Lisi to help."

(44) *Gen Zhangsan, yinwei ni bu yao shuohua, wo zhihao qing le Lisi bangmang. with Zhangsan because you not want talk, I to obliged ask PERF Lisi help

(45) ? Zicong gen na ge nuhaizi ni jiehun le, zhe ge jia jiu meiyou yike anning. since with that CLgirl you marry PERF this CL house then not have a moment quietness "Ever since that girl you married, this house hasn't had a quiet moment."

(46) *Gen na ge nuhaizi zicong ni jiehun le, zhe ge jia jiu meiyou yike anning. With that-CL girl since you marry PERF this CL house then not have a moment quietness

The contrasts above show that COMP precedes LD. The only problematic sentence is (45), whose marginality may be due to the presence of two prepositions next to each other ${ }^{10}$. Summarizing, just like it is shown by Benincà and Poletto (2004) for Italian, in Chinese as well HT precedes COMP, which precedes LD.

Notice also, that, like in Italian, only LD are allowed in relatives:

(47) a. Yi ge [Zhangsan bu hui gei Lisi mai de] dongxi .... One-CL Zhangsan not will to Lisi buy REL thing

"One thing Zhangsan won't buy for Lisi..."

b. Yi ge [gei Lisi Zhangsan bu hui mai de] dongxi .... One CL to Lisi Zhangsan not will buy REL thing

"One thing for Lisi Zhangsan won't buy..."

(48) a. Na yi ben [Zhangsan bu hui gei Lisi mai de] shu .... that-one CL Zhangsan not will to Lisi buy REL book

"The book that Zhangsan won't buy for Lisi..."

b. Na yi ben [gei Lisi Zhangsan bu hui mai de] shu .... That one CL to Lisi Zhangsan not will buy REL book

"The book that for Lisi Zhangsan won't buy..."

\footnotetext{
${ }^{10}$ The lexical item zicong is strictly speaking a prepositions, but in the context considered here, it is able to introduce sentences. It is for this reason that we consider it as occurring in $\mathrm{C}$, regardless of its status as a preposition or a complementizer (for more on this, see Huang, Li and Li (forthcoming)).
} 
(47.a) and (48.a) illustrate relative clauses without topicalization, in (47.b) and (48.b) the dative PP is topicalized inside the relative clause. Since it is a PP, it has to be a LD, therefore the sentences above show that LD is allowed in relatives. Now, compare the examples above with the following one:

(49) *Yi ge [Lisi, Zhangsan bu hui gei ta mai de] dongxi... One CL Lisi Zhangsan not be-able to him buy REL thing

Here, the element topicalized is bare, but it is linked to the PP in the sentence, hence it has to be a HT. The sentence is ungrammatical, showing that HTs are not allowed within relatives in Chinese.

\section{HT vs. Aboutness}

One of the reasons for which Chinese is considered a "topic-prominent language" (or for some, a "discourse-prominent language"), is because it allows Topics that have no grammatical connection with the rest of the sentence, in the sense that there is no element that can directly be linked to them. These are the so-called Aboutness Topics, of which we provide an example below:

(50) Hua (a), wo zui bu xihuan meiguihua.

Flowers PART I most not like roses

"Among flowers, I dislike roses very much."

In (50), the nominal hua is not related to any position in the sentence, as there is no trace or pronoun linked to it, as a matter of fact, it is not even subcategorized by the verb. Given the characteristics of HT, it comes natural to ask whether these actually correspond to HTs. In this section, we show that this is not the case. We'll see that Aboutness Topics do not qualify as HTs, as they do not share their characteristics entirely. Moreover, Aboutness Topics can occur not only with LDs, but with HTs as well, showing that they need to be considered different both from LD and HT.

We have chosen to test two types of Aboutness Topics: "whole-part" Aboutness Topics and "possessive" ones. The former establish a whole-part relation (see examples (51) and (52)) between the Topic and the resumptive element in the comment; the latter establish a "possessive" relation (see example (53) and (54)):

(51) Shi ge li, wu ge lan le. Xu \& Langendoen (1985: 75a) ten CL pear five CL spoil PERF

"Of the ten pears, five have spoiled."

(52)Wo de jiaren, jintian wo kanjian baba le. I DE family-people today I saw father MOD "Of my family, today I saw my father."

(53) Nei ke shu, yezi da. Li \& Thompson (1976: 23) that CL tree leave big

"That tree, the leaves are big."

(54) Zhe ge ren, wo juede jixing tebie hao. this CL man I feel memory exceptionally good "As for this man, I feel his memory is exceptionally good." 
In order to test whether Aboutness Topics qualify as Hanging Topics, we test them against the diagnostic features that characterize HTs. At first sight, these two kinds of Topic seem to be very similar. Both of them require a resumptive element: in the case of HT, such resumptive element is a tonic pronoun or an epithet; in the case of Aboutness Topic, instead, it is a more specific DP resuming a more general one, as we can see in the examples above. Just like HT, Aboutness Topic does not agree in Case with the coreferent resumptive element inside the predicate (IP), as in the examples below:

(55) Wo de jiaren, wo bu neng gen baba kai wanxiao.

I DE family-people I not can with father joke

"In my family, I can't joke with my father."

(56) Ta de jiaren, ta dui mama zongshi hen reqing.

He DE family-people he to mother always very polite

"Of his family, he's always very polite to (his) mum."

With respect to the other diagnostic features, though, Aboutness Topics behave differently from HTs. The examples in (57)-(60) below show that an Aboutness Topic can be a Prepositional Phrase, differently from HT, which can only be a Bare DP:

(57) Guanyu zhe shi ge li, wu ge lan le. As for this ten CL pear five CL spoil PERF

"As for this ten pears, five have spoiled."

(58) Zhiyu wo de jiaren, jintian wo kanjian baba le. As for I DE family-people today I saw father PERF

"As for my family, today I saw my father."

(59) Guanyu nei ke shu ma, yezi da.

As for that CL tree PART leave big

"As for that tree, leaves are big."

(60) Guanyu zhe ge ren ma, wo juede jixing tebie hao. As for this CL man PART I feel memory exceptionally good "As for this man, I feel his memory is exceptionally good."

Multiple HTs are not possible, instead multiple Aboutness Topics are grammatical:

(61) Wo de jiaren, wo de fumu, muqin yijing tuixiu le. I DE family-people I DE parents mother already retire PERF

"As for my family, as for my parents, my mother already retired."

(62) Wo de huayuan, na ke shu, yezi da.

I DE garden that CL tree leave big

"In my garden, that tree, leaves are big."

(63) Shuiguo, pingguo, wo chi le liang ge. fruit apple I eat PERF two CL

Gasde slightly modified (2000, pg.4)

"As for fruits, as for apples, I ate two."

(64) Suoyou de ren, zhe ge ren, wo juede jixing tebie hao. 


\section{All DE man this CL man I feel memory exceptionally good}

"Among all the men, as for this man, I feel his memory is exceptionally good."

(65) Wo pengyoumen, Zhangsan, wo juede jixing tebie hao.

I friends Zhangsan I feel memory exceptionally good

"Among my friends, as for Zhangsan, I feel his memory is exceptionally good."

Not only do Aboutnes Topics fail to show all the features that characterize HTs, but they can also cooccur with them (as with LDs). The examples in (66) and (67) show that Aboutness Topics can occur with LDs, and those in (68) and (69) show that they can occur with HTs:

- $\quad$ Aboutness Topic $>$ LD

(66) Wo suoyou de pengyou, dui Zhangsan, wo yijing shuo hua. $I$ all DE friend to Zhangsan I already speak word "Among all my friends, to Zhangsan, I already spoke."

(67) Wo de jiaren, ti/wei baba, Zhangsan yijing jiedao hen duo qian le. I DE family-people for father Zhangsan already borrow very much money MOD "As for my family, for my father, Zhangsan already borrowed a lot of money."

- Aboutness Topic $>$ HT

(68) Wo de jiaren, baba, wo zuotian kanjian ta le, mama, wo hai mei kanjian ta le. I DE family-people father I yesterday saw him MOD mother I yet not saw her MOD "As for my family, as for my father, I saw him yesterday, as for my mother, I didn't see her yet."

(69) Wo de jiaren, baba, Zhangsan yijing gen ta tan guo le. I DE family-people father Zhangsan already with him speak EXP MOD

"As for my family, as for my father, Zhangsan already spoke with him."

The above examples, in contrast with the following ones, show that Aboutness Topics precede both HT and LD. ${ }^{11}$

- $\quad *$ HT $>$ Aboutness Topic

\footnotetext{
(i) *Meiguihua, hua, wo hen xihuan. roses flowers I very like

(ii) Le rose, tra i fiori, mi piacciono molto. the roses among the flowers to-me please much 'Roses, among flowers, I like a lot.'
}

${ }^{11}$ As Paul pointed out to us, the examples from (70) to (73) in the text are ungrammatical because of a semantic restriction about the order of the elements. In Chinese, it is not possible to put a nominal that refers to a smaller group to the left of (or dominating) a nominal that refers to a bigger one. This order is instead available in Italian:

This semantic restriction seems to be reflected in the structure of the sentences in Chinese, as the examples in section 4 show. For the reasons of this parametric difference, at this point we can simply speculate that it may have to do with the existence of Aboutness Topic in Chinese (but not in Italian) and the difference use of prepositions for this kind of scene-setting topics in the two languages. Notice also that in (ii) tra i fiori could be read as a parenthetical. In which case, it would be a completely different structure. As to why it is nevertheless unavailable in Chinese, we can't offer a solution at this point. 
(70)* Baba, wo de jiaren, wo zuotian kanjian ta le, mama, wo hai mei kanjian ta le. Father I DE family-people I yesterday saw him MOD mother I yet not saw her MOD

(71)*Baba, wo de jiaren, Zhangsan yijing gen ta tan guo le. Father I DE family-people Zhangsan already with him speak EXP MOD

- $\quad *$ LD $>$ Aboutness Topic

(72) *Baba, wo de jiaren, wo zuotian kanjian le, mama, wo hai mei kanjian le. Father I DE family-people I yesterday saw MOD mother I yet not saw MOD

(73) *Ti/wei baba, wo de jiaren, Zhangsan yijing jiedao hen duo qian le. for father I DE family-people Zhangsan already borrow very much money PERF

When Aboutness Topics cooccur with HT and/or LD, their relative order is: Aboutness Topic $>$ HT $>$ LD, as illustrated by the following examples:

- $\quad$ Aboutness Topic $>$ HT $>$ LD

(74) Wo de jiaren, baba, cong na jia yinhang, wo yijing ti/wei ta jiedao hen duo qian le. I DE family-people father from that-CL bank I already for him borrow very much money $M O D$

"As for my family, my father, from that bank, I already borrowed a lot of money for him."

- $\quad *$ HT $>$ Aboutness Topic $>$ LD

(75) *Baba, wo de jiaren, cong na jia yinhang, wo yijing ti/wei ta jiedao hen duo qian le. money $M O D$ Father I DE family-people from that-CL bank I already for him borrow very much

- $\quad * \mathrm{HT}+\mathrm{LD}+$ Aboutness Topic

(76) *Baba, cong na jia yinhang, wo de jiaren, wo yijing ti/wei ta jiedao hen duo qian le. Father from that-CL bank I DE family-peopleI already for him borrow very much money $M O D$

The results of the diagnostic tests above allow us to claim that Aboutness Topics do not correspond to HTs, but they occupy another functional projection in a position higher than both HT and LD.

\section{Topic and Focus: ordering constraints}

\subsection{Methodology}

In this section, we investigate the relative order between Focus and Topic. In our investigation we consider two kinds of Foci and we try to individuate their positions in Chinese:

1. lian...dou/ye Focus construction, i.e.even-Focus: 
even Mary Zhangsan think Lisi all not like

"Even Mary, Zhangsan thinks that Lisi also doesn't like (her)."

2. Focus with contrastive stress (indicated below by the use of capital letters) without Focus marker:

(78) Zhangsan renwei [CP Lisi bu xihuan MALI].

Zhangsan think Lisi not like Mary

"Zhangsan thinks Lisi doesn't like MARY."

We also investigate whether contrastive Focus is base-generated in-situ, or moved to the Left Periphery.

In our analysis, we also consider the two main types of Topic, namely Topic linked to a trace, or a pro or a resumptive element and Aboutness Topic. The first category, we saw above, can be further split into HT and LD. We shall look at the occurrence of Focus elements with respect to these two types of Topics as well. We repeat below two sentences exemplifying respectively LD and/or HT and Aboutness Topic:

1. HT/LD. It is linked to a trace, a pro, or a resumptive pronoun or epithet in the sentence/comment. When linked to a trace, it is derived by movement (see discussion in section 2.3. for evidence in this sense). When it is linked to a pro or a resumptive pronoun or epithet, it is base-generated.

(79) Zhei ge ren $\mathrm{i}_{\mathrm{i}}$ me, wo jian guo $t_{\mathrm{i}}$. this CL person PART I see EXP

"This person, I have already met."

2. Aboutness Topic. It doesn't have a corresponding gap in the sentence/comment, it is linked to a resumptive element, but it crucially differs from HT, as we discussed in section 4 above.

(80) Chezi a, Zhangsan xihuan kache.

(Shyu, 1995, Ch. 3: 52)

Car PART Zhangsan like truck

"As for cars, Zhangsan likes trucks."

\subsection{Results of the Tests for Topic and Focus ordering}

To test Focus with contrastive stress without Focus marker, we always used a question whose relative answer is a "correction". In this section, we test moved and base-generated Topic vs. Focus. For moved Topics, we use example of LDs, and for base-generated Topic, we use Aboutness ones. In section 5.3, we test the occurrence of both LD and HT vs. Focus.

- $\quad$ Moved Topic $>$ Focus (with contrastive stress) moved to the Left Periphery

(81) (i) Zhangsan Z $_{\mathrm{i}}$ a, ti chi le pingguo ma? Zhangsan PART eat PERF apple PART

"As for Zhangsan, did he eat apples?"

(ii) * Zhangsan ${ }_{\mathrm{i}} \mathrm{a}, \quad$ PUTAO $_{\mathrm{j}}, \mathrm{t}_{\mathrm{i}}$ chi le $\mathrm{t}_{\mathrm{j}}$. Zhangsan PART grapes eat PERF 
(81.ii) shows that contrastive Focus moved to the LP is not accepted by the speakers. The sentence is bad.

- $\quad$ Moved Topic > even- Focus

(82) Zhangsan Z $_{\mathrm{i}}$ a, lian Xiaoyu $\mathrm{u}_{\mathrm{j}}, \mathbf{t}_{\mathrm{i}}$ dou piping le $\mathbf{t}_{\mathrm{j}}$. Zhangsan PART even Xiaoyu all criticize PERF

"As for Zhangsan, even Xiaoyu, he criticized."

(82) shows that the moved Topic is in a higher position than the even-Focus position.

Based-generated Topic $>$ Focus with contrastive stress moved to the LP

(83) Hua (a), MEIGUIHUA $A_{i}$, wo zui bu ai $\mathrm{t}_{\mathrm{i}}$. Flowers PART roses I most not love

"Among flowers, ROSES, I dislike most."

In (83) we can see the base-generated Topic on the left of the stressed Focus. Contrary to the example in (81 ii), this sentence seems to show that in Chinese a stressed Focus is moved to the LP. But Paul (personal communication) explains the grammaticality of this sentence claiming that meiguihua is not a Focus, but a Contrastive Topic. ${ }^{12}$ Considering that, except for (83), all other examples with stressed Focus moved to LP are ungrammatical, we shall adopt Paul's explanation of (83). In section 5.4. we'll show that this type of contrastive NP is indeed Topic and not Focus.

- $\quad$ Base-generated Topic $>$ even-Focus

(84) Hua, lian meiguihua $\mathrm{j}_{\mathrm{j}}, \mathbf{t}_{\mathrm{j}}$ dou hen pianyi.

Flowers even roses all very cheap

"As for flowers, even roses are cheap."

As in (82), the example (84) shows that Topic, in this case base-generated, in a position on the left of even-Focus, is grammatical.

- $\quad$ Focus with contrastive stress moved to the LP $>$ Moved Topic

(85) (i) Zhangsan Z $_{\mathrm{i}} \mathrm{a}, \mathrm{t}_{\mathrm{i}}$ chi le pingguo ma?

Zhangsan PART eat PERF apple PART

"As for Zhangsan, did he eat apples?"

(ii) *PUTAO ${ }_{\mathrm{j}}$, Zhangsan $\mathrm{i}$ a, $\mathbf{t}_{\mathrm{i}}$ chi le $\mathbf{t}_{\mathrm{j}}$ grapes Zhangsan PART eat PERF

${ }^{12}$ Another example of Contrastive Topic in Chinese is given by sentences as the following ones, both taken from Paul (2006):

(i) Shanghai, wo yijing qu-guo le, keshi Tianjin, [wo ] hai mei qu-guo

Shanghai $1 S G$ already go-EXP but Tianjin 1 SG still NEG go-EXP

"I have already been to Shanghai, but Tianjin, I have not been there yet."

(ii) Zhei-ge xuesheng, wo xihuan, nei-ge xuesheng, wo bu xihuan

this-CL student 1SG like that-CL ISG NEG like

"This student, I like, that one, I don't."

Notice that these specific Topics could also be interpreted as List Interpretation ones (see Benincà and Poletto 2004).

Here, we won't look at these cases, and we'll leave their final characterization for future research. 
In (85) we test the opposite order that we find in (81), and once again the sentence with Focus with contrastive stress moved to the LP is bad, independently of its position with respect to the moved Topic:

- $\quad$ even-Focus $>$ Moved Topic

(86) ?? Lian $\mathrm{Xiaoyu}_{\mathrm{j}}$, Zhangsan $\mathrm{i}_{\mathrm{i}}$ a, $\mathbf{t}_{\mathrm{i}}$ dou piping le $\mathbf{t}_{\mathrm{j}}$. Even Xiaoyu Zhangsan PART all criticize PERF

"Even Xiaoyu, as for Zhangsan, , he didn't criticize."

In (86) we test even-Focus in a position higher than the moved Topic position: the opposite order of (82). In this case the clause is bad.

- $\quad$ Focus with contrastive stress moved to the LP $>$ Base-generated Topic

$(87) *$ MEIGUIHUA $A_{j}$, hua, $\mathbf{t}_{\mathrm{j}}$ hen piaoliang. Roses flowers very beautiful

"ROSES, as for flowers, are beautiful."

The example in (87) shows that if Focus with constrastive stress is on the left of the base-generated Topic, the sentence is ungrammatical.

- $\quad$ even-Focus $>$ Base-generated Topic

(88) *Lian meiguihua $\mathrm{j}_{\mathrm{j}}$ hua, $\mathbf{t}_{\mathbf{j}}$ dou hen pianyi.

Even roses flowers all very cheap

In (88) we verify the ungrammaticality of even-Focus in a position higher than the base-generated Topic position.

On the base of the results of the diagnostic tests above, we are able to establish that in Chinese the relative order of Topic and Focus is:

(89) TOPIC > lian-FOCUS

(89) illustrates that, in the CP area, all Topics are on the left of lian-Focus, regardless of whether they are moved Topics or base-generated ones. This confirms what established by Paul (2005) with the difference that in our approch we distiguish different types of Topics.

This is also maintained by Gao (1994) for slightly different examples, and Paris (1998) reached the same results, for clefts and Topics.

We also established that Focus with contrastive stress without Focus marker, moved to the LP, doesn't seem to be possible in Chinese (see also Gao 1994).

\subsection{Relative order LD/HT vs. Focus}

In this section we test the occurrence of even-Focus with either HT or LD to verify their relative order. On the basis of the tests in section 5.2, we expect that both types of Topic precede the evenFocus. In (90), we test the lian construction with a gap in IP. (90.a) is the base-sentence from which we derive the Left Dislocation of the PP on the left of even-Focus. The sentence is good.

(90) a. Lian na ben hen gui de shu even that $C L$ very expensive DE book, Lisi all to Xiaoyu buy-PERF 

"Even that expensive book, Lisi bought for Xiaoyu."
b. Gei Xiaoyu, lian na ben hen gui de shu to Xiaoyu even that CL very expensive DE book, Lisi all buy-PERF
"For Xiaoyu, even that expensive book, Lisi bought."

The example in (91) shows that the order with even-Focus higher than LD in the structure is ungrammatical:

(91) *Lian na ben hen gui de shu Even that CL very expensive DE book to Xiaoyu, Lisi all buy PERF

(92) shows the HT in a position higher than even-Focus position. The sentence is good. In (93) we test the opposite order and the sentence is ungrammatical:

(92) $X_{\text {iaoyu }}$, lian na ben hen gui de $\mathrm{shu}_{\mathrm{j}}$, Lisi dou gei ta mai le $t_{\mathrm{j}}$. Xiaoyu even that $C L$ very expensive DE book Lisi all to her buy PERF "Xiaoyu, even that expensive book, Lisi bought for her."

(93) *Lian na ben hen gui de $\mathrm{shu}_{\mathrm{j}}$, Xiaoyu $\mathrm{u}_{\mathrm{i}}$, Lisi dou gei ta $\mathrm{i}_{\mathrm{i}}$ mai-le $t_{\mathrm{j}}$. even that CL very expensive DE book Xiaoyu Lisi all to her buy-PERF

The ungrammaticality of (93) confirms that even-Focus cannot be on the left of HT.

To conclude, as we expected, the relative order between LD or HT and even-Focus is:

(94) LD > even-Focus

HT $>$ even-Focus

Further considering the results of the diagnostic tests in the section 3.1 (exx. (32) and (33)), namely the fact that the relative order between HT and LD is HT> LD, we can confirm our expectations, i.e. both types of Topic precede the even-Focus, in the following order:

(95) $\mathrm{HT}>$ LD > even-Focus

\subsection{On Contrastive Topic}

In section 5.2. we have analyzed the contrastive nominal in the following sentence as a Contrastive Topic, following Paul (2005):
(96) Hua
(a), MEIGUIHUA $\mathrm{i}_{\mathrm{i}}$, wo zui bu ai $t_{\mathrm{i}}$.
Flowers PART roses
I most not love
"Among flowers, ROSES, I dislike most."

In this section, we'll show that this type of contrastive NP is indeed Topic and not Focus. In order to prove this, we shall use the following tests:
1. WCO
2. Cooccurrence with other Foci

As for the first test, following Benincà and Poletto (2004), we assume that WCO effects occur only with focus, as these are operator-like elements, and not with Topics. Therefore, if the contrastive 
nominal in (96) above is a Topic, we expect no WCO, if instead it is a Focus, we do. For pragmatic reasons, we have changed our example slightly. In (97) below, we have an Aboutness Topic, followed by a moved contrastive nominal, baba:

(97) Wo de jiaren, $\quad$ BABA , wo zui xihuan $t_{\mathrm{i}}$.

I DE family-people father I most like

"Of my family members, it's my dad who I like the best."

The following sentence shows that there are no WCO effects:

(98) Wo de jiaren, $\quad \mathrm{BABA}_{\mathrm{i}}$, [piping ta $\mathrm{i}_{\mathrm{i}}$ de] ren hai hen xihuan $t_{\mathrm{i}}$.

I DE family-people father critizice him REL people still very like

Intended meaning: "Of my family members, it's my father who the people that criticize him still like him."

The second test is based on the assumption that two types of Foci cannot cooccur. One way, in fact, to distinguish Topic from Focus is based on the fact that there should be a unique structural Focus position, as focalization of two elements is excluded (Benincà, 1988; Rizzi, 1997), while Topics can in theory iterate. So, if we test multiple even-Foci, we find that the sentence is ungrammatical.

(99) *Lian Zhangsan ${ }_{i}$, lian Xiaoyu $\mathbf{u}_{\mathrm{j}}, \mathbf{t}_{\mathrm{i}}$ dou piping le $\mathbf{t}_{\mathrm{j}}$. Even Zhangsan even Xiaoyu all criticize PERF

On the contrary, multiple Topics are OK, i.e. two Topics can cooccur (see Paul, 2005, among others):

(100) Cong zhejia yinhang $\mathrm{i}_{\mathrm{i}} \mathrm{t} /$ wei Zhangsan $_{\mathrm{j}}$ wo zhidao women keyi jiedao hen duo qian. $(=(31))$ from this-CL bank for Zhangsan I know we can borrow very much money 'From this bank, for Zhangsan, I know we can borrow a lot of money.'

The two examples below show that lian-Focus can occur with a contrastive nominal:

(101) Hua (a), MEIGUIHUA ${ }_{\mathrm{i}}$, lian Zhangsan $_{\mathrm{j}}$, ta $\mathrm{ta}_{\mathrm{j}}$, dou ai $\boldsymbol{t}_{\mathrm{i}}$. Flowers PART roses even Zhangsan he all love

"Among flowers, it's roses that even Zhangsan loves."

(102) Hua (a), MEIGUIHUA Flowers PART roses even Zhangsan he all not very like

"Among flowers, it's roses that even Zhangsan dislikes a lot."

The examples in (101) and (102) above show that contrastive topics and lian-Focus can cooccur, hence they do not compete for the same position and one of the two cannot be considered a real Focus. Summarizing, we take the contrastive nominals described in this section to be Contrastive Topics (either HT or LD), but not contrastive Foci.

\section{Conclusions and open issues}

The Left-Periphery of Chinese is organized as follows: 
(103) Aboutness Topic $>$ HT $>$ LD $>$ lian-Focus $>$ IP

HT and LD can be stressed phonologically and act as Contrastive Topics.

As for embedded contexts, we have found that both LD and HT are possible, and that the relative order is:

(104) HT > COMP > LD

In relatives, only LD are admitted, just like in Italian.

We have also established that HT are always linked to a resumptive pronoun or an epithet, while LD are always linked to a gap. The seemingly free occurrence of resumptive pronouns with topic structures (when either the object or the subject is topicalized) is due to the fact that it is impossible to distinguish among HT and LD in these cases.

Our investigation has confirmed that contrastive bare Focus in Chinese does not move to the Left Periphery.

Going back to our initial questions, we have found that Chinese seems to show the same ordering restrictions found in Italian with respect to Topic and Focus. More specifically, there is a distinction between HT and LD Topics, and these both precede Focus. Both are allowed in embedded context, but only LD is allowed in relatives. Chinese does not allow bare focalization strategies in the Left Periphery. The fact that Chinese is a "Topic-Prominent language" seems to play a role in the sense that it seems to allow more types of Topics than Romance languages do, in particular, it allows base-generated Topics without either gaps or strictly resumptive elements ('Aboutness Relationship' ones).

We can draw the following theoretical conclusions. The fact that Focus and question formation in Chinese adopt the same in-situ strategy tells us that they belong to the same category: operator-like elements. This is interesting, because it sets them apart from Topics, as expected. And it would help us discern whether Topics in Chinese (gapped ones) are operator-like elements (Huang, Li and Li (forthcoming), among others) or not (Ning 1993). But more work needs to be done. Also, it seems relevant to note that different focus strategies adopt different syntactic behaviours: lian-Focus moves to the Left Periphery, while bare Focus doesn't. This also raises the issue of the ultimate nature of the lian-focus construction, which, when it occurs in the Left Periphery, seems to have the behaviour both of a Topic and of a Focus. In this paper, we decided to consider it a Focus, leaving aside for the moment the question of how to deal with its Topic-like properties.

In a sense, then, the Left Periphery of Chinese takes a heavier burden as far as Topics are concerned, but a lighter one as far as Foci are. Why would that be? In other words, what are the parameters that distinguish Italian from Chinese with respect to Topic and Focus? And what does that tell us about the one-to-one correspondence between pragmatic/semantic function and syntactic position? We leave these open issues for future research.

\section{References}

Abbiati, M. (1998), Grammatica di Cinese Moderno, Venezia: Cafoscarina.

Abbiati, M. (1990), La nozione di soggetto nella teoria grammaticale: il caso della lingua cinese moderna, Annali di Ca' Foscari: Rivista della Facolta di Lingue e Letterature straniere dell'Universita di Venezia 29, $3,227-245$. 
Abbiati, M. (1990), La nozione di tema nella teoria grammaticale: il caso della lingua cinese moderna, Cina $22,167-200$.

Bartos, H. (2003), Locating the Subject in Mandarin Chinese, Acta Orientalia Hungarica 56, 149-172.

Belletti, A. ed. (2004), Structures and Beyond. The Cartography of Syntactic Structures, vol.3, New York \& Oxford: Oxford University Press.

Benincà, P. (1988), L'ordine degli elementi della frase e le costruzioni marcate, in Renzi L (a cura di) Grande grammatica di consultazione, vol. I, Bologna, Il Mulino, 142-143.

Benincà, P. (2001), The position of Topic and Focus in the left periphery. In G. Cinque \& G. Salvi eds., Current Studies in Italian Syntax. Essays Offered to Lorenzo Renzi, Amsterdam: Elsevier-North Holland, 39-64.

Benincà, P. (2004), The Left Periphery of Medieval Romance, Journal: Studi Linguistici e Filologici Online, Vol: 2 pp. $243-297$

Benincà, P. \& Cecilia Poletto (2004), Topic, Focus and V2: Defining the CP sublayers. In Rizzi ed. (2004), $52-75$.

Brunetti, L. (2003), A unification of Focus, Ph.D. Dissertation, Università di Firenze.

Chafe, W. (1976), Giveness, Contrastiveness, Definiteness, Subjects and Topics, in C. N. Li ed (1976), 2555.

Chao, Y.-R. (1968), A grammar of spoken Chinese, Berkeley: University of California Press.

Chierchia, G. (1995), Dynamics of Meaning: Anaphora, Presupposition, and the Theory of Grammar. The University of Chicago Press: Chicago and London.

Cinque, G. (1990), Types of Abar-dependencies, MIT Press, Cambridge, Mass.

Cinque, G. (1999), Adverbs and Functional Heads. A Cross-Linguistic Perspective, New York \& Oxford: Oxford University Press.

Cinque, G. ed. (2002), Functional Structure in DP and IP. The Cartography of Syntactic Structures, vol.1, New York \& Oxford: Oxford University Press.

Fauconnier, G. (1975), Pragmatic Scales and Logical Structures, Linguistic Inquiry 6, 353-75.

Gao, Q. (1994), Focus Criterion: Evidence from Chinese, Proceedings of the Sixth North American Conference on Chinese Linguistics, University of Southern California.

Gasde, H. \& Waltraud Paul (1996), Functional categories, topic prominence and complex sentences in Mandarin Chinese, Linguistics 34: 263-294.

Gasde, H. (1999), Are "Topic-Prominence" and "Subject-Prominence" relevant typological parameters?, First Meeting of the European Association of Chinese Linguistics. EHESS, CRLAO, Paris.

Gasde, H. (2000), Li and Thompson's parameter of Topic-Prominence reconsidered against the background of Mandarin Chinese and German, International Symposium on Topic and Focus in Chinese. Hong Kong Polytechnic University.

Hole, D. (2004), Focus and Background Marking in Mandarin Chinese: System and Theory Behind Cai, Jiu, Dou and Ye. London \& New York: RoutledgeCurzon. 
Horn, L. R. (1969), A Presuppositional Analysis of Only and Even, CLS 5, 98-107.

Karttunen, L. \& Stanley Peters. (1979), Conventional Implicature. In Choon-Kyu Oh and and D. A. Dineen (Eds.), Syntax and Semantics, Volume 11: Presupposition (pp. 1-55). New York: Academic Press.

Huang, C. -T. J. (1982), Logical relations in Chinese and the theory of grammar. PhD dissertation, MIT. Published by Garland Publishing, Inc., New York, in 1989.

Huang, C.-T. J. (1987), Remarks on empty categories in Chinese, Linguistic Inquiry 18, 321-337.

Huang, C. T. J., Audrey Li \& Yafei Li (forthcoming), The Syntax of Chinese, Cambridge University Press.

Lee, C. (1999), Contrastive Topic: a Locus of the Interface Evidence from Korean and English, in Turner K. (ed.), The Semantics/Pragmatics Interface from different points of view, Elsevier Science: 317-342.

Li, B. (2006), Chinese Final Particles and the Syntax of the Periphery, PhD Dissertation, Universiteit Leiden.

Li, C. N. \& Sandra A. Thompson (1976), Subject and Topic, New York: Academic Press.

Li, C. N. \& Sandra A. Thompson (1976), Subject and Topic: a new Typology of language, in Li, Charles N. (ed.): 457-489.

Li, C. N. \& Sandra A. Thompson (1981), Mandarin Chinese: A Functional Reference Grammar, Los Angeles: University of California Press.

Li, Y.-H. A. (1990), Order and constituency in Mandarin Chinese. Dordrecht: Kluwer Academic Publishers.

Li, Y.-H. A. (2000), Topic Structures and Minimal Effort, ZAS Papers in Linguistics 20:1-20.

Lu, P. (2003), La Subordination Adverbiale en Chinois Contemporain, PhD Dissertation, Université Paris 7.

McCloskey, J. (2002), Resumption, Syncom.

Ning, C. (1993), The Overt Syntax of Relativization and Topicalization in Chinese. Ph.D. Dissertation, Irvine: University of California.

Pan, H. \& Jianhua Hu (2002), Licensing Dangling Topics in Chinese, paper presented at the 2002 LSA Annual Meeting, San Francisco, CA, USA.

Paris, M.-C. (1979a), Some aspects of the syntax and semantics of the lian...ye/dou costruction in Mandarin, Cahiers de linguistique - Asie orientale 5: 47-70.

Paris, M.-C. (1998), Focus Operators and Types of Predication in Mandarin, Cahiers de Linguistique-Asie Orientale 27.2: 139-159.

Paris, M.-C. (1999), Ordre des mots, topique et focus en chinois contemporain. In C. Guimier ed. $L a$ thématisation dans les langues. Actes du Colloque de Caen, 9/11-10-1997.

Paul, W. (2005), Low IP and left periphery in Mandarin Chinese, Recherches Linguistiques de Vincennes, vol. 33: 111-134.

Paul, W. (2006), What the topic is (not) about: the Case of Mandarin Chinese, Ms, CRLAO, EHESS, Paris

Qu, Y. (1994), Object Noun Phrase Dislocation in Mandarin Chinese, Ph.D. Dissertation, University of British Columbia. 
Rizzi, L. (1997), The fine structure of the left periphery. In L. Haegeman ed., Elements of Grammar. Handbook of Generative Syntax, Dordrecht: Kluwer, 281-337.

Rizzi, L. ed. (2004), The Structure of CP and IP. The Cartography of Syntactic Structures, vol.2. New York \& Oxford: Oxford University Press.

Shi, D.-X. Tim (1992a), The Nature of Topic Comment Constructions and Topic Chains, Ph.D. Dissertion, University of Southern California.

Shi; D.-X. Tim (2000), Topic and Topic-comment constructions in Mandarin Chinese, Language 76, 2: 383408.

Shyu, S. (1994), Focalization: a case in Mandarin Chinese. Proceedings of the Sixth North American Conference on Chinese Linguistics. University of Southern California.

Shyu, S. (1995), The Syntax of Focus and Topic in Mandarin Chinese, Ph.D. Dissertation, University of Southern California.

Smits, R. J. C. (1989), The relative and cleft constructions of the Germanic and Romance languages, $\mathrm{PhD}$ Dissertation, KUB, Tilburg, Dordrecht: Foris.

Tang, C.-C. J. (1990), Chinese Phrase Structure and the Extended X'-Theory, PhD Dissertation, Cornell University.

Tsai, D. (1994), On economizing the theory of A-bar dependencies, PhD Dissertation, MIT, Cambridge, Mass.

Xu L. \& D. Terence Langendoen (1985), Topic Structures in Chinese, Language 61, 1: 1-27.

Xu, L. (1986), Free empty categories, Linguistic Inquiry 17: 75-93.

Xu, L. (2001), The topic-prominence parameter. In Haihua Pan (ed.), Studies in Chinese Linguistics II. Hong Kong: The Linguistic Society of Hong Kong, 209-234.

Zhang, N. (2002), Island Effects and Episodic Eventualities in Chinese Topicalization. Linguistics by Heart: in honor of Horst-Dieter Gasde, ed. by D. Hole, P. Law, and N. Zhang. ZAS-Berlin. 